Jurnal Gizi Klinik Indonesia

Vol. 16 No. 2, Oktober 2019 (81-86)

ISSN 1693-900X (Print), ISSN 2502-4140 (Online)

Tersedia online di https://jurnal.ugm.ac.id/jgki

DOI: https://doi.org/10.22146/ijcn.27617

\title{
Kepatuhan konsumsi suplemen mikronutrien tidak terpengaruh oleh bentuk suplemen
}

\author{
Compliance of micronutrients supplement consumption was not affected by supplements form
}

\author{
Faurina Risca Fauzia1, Arta Farmawati ${ }^{2}$, Lily Arsanti Lestari ${ }^{3,4 *}$
}

${ }^{1}$ Program Studi S1 Gizi, Fakultas Ilmu Kesehatan Universitas ‘Aisyiyah Yogyakarta

${ }^{2}$ Departemen Biokimia, Fakultas Kedokteran, Kesehatan Masyarakat, dan Keperawatan Universitas Gadjah Mada

${ }^{3}$ Departemen Gizi Kesehatan, Fakultas Kedokteran, Kesehatan Masyarakat, dan Keperawatan Universitas Gadjah Mada

${ }^{4}$ Institute for Halal Industry and System Universitas Gadjah Mada

\begin{abstract}
Background: Taburia is micronutrient sprinkle produced by Ministry of Health Indonesia to overcome malnutrition problem in Indonesia. Compliance of Taburia consumption is an important indicator for the success of the supplementation program. Taburia's compliance in some regions is low (<80\%). Gummy candies are children's favorable food product. Objective: To evaluate the compliance of micronutrient consumption in the form of sprinkle and gummy candies in children. Methods: This study was a quasiexperimental study with randomized control group design. Respondents are mother and children aged 36-59 months in Yogyakarta District. The children received supplementation of Taburia sprinkle or fortified gummy candies for 30 days. Results: The compliance of Taburia sprinkle and fortified gummy candies were $85.39 \%$ and $80.32 \%$ respectively, however it was not significantly different $(p>0.05)$. Several factors affected the compliance level such as mother's employment status, gender of the children, and age of the children. Conclusions: The compliance level of Taburia sprinkle and fortified gummy candies was similar. Hence fortified gummy candies could be used as an alternative of micronutrient supplement to overcome nutrition problem in Indonesia.
\end{abstract}

KEYWORDS: compliance; gummy candies; micronutrients supplement; sprinkle

\begin{abstract}
ABSTRAK
Latar belakang: Taburia merupakan suplemen berisi mikronutrien berbentuk bubuk yang diproduksi oleh Kementerian Kesehatan Indonesia untuk mengatasi masalah gizi di Indonesia. Kepatuhan konsumsi Taburia merupakan indikator keberhasilan program supplementasi. Kepatuhan konsumsi Taburia di beberapa wilayah Indonesia masih rendah $(<80 \%)$. Permen jelly merupakan produk makanan yang disukai anak-anak. Tujuan: Penelitian ini bertujuan untuk mengetahui kepatuhan konsumsi suplemen mikronutrien dalam bentuk bubuk dan permen jelly pada anak balita. Metode: Penelitian kuasi eksperimental dengan rancangan randomized control group design. Responden penelitian yaitu ibu dan anak balita sehat usia 36-59 bulan di wilayah Yogyakarta. Anak-anak diberi Taburia atau permen jelly yang difortifikasi selama 30 hari intervensi. Hasil: Kepatuhan konsumsi Taburia dan permen jelly yang difortifikasi adalah berturut-turut $85,39 \%$ dan $80,32 \%$ tetapi tidak berbeda secara signifikan ( $\mathrm{p}>0,05)$. Beberapa faktor dapat mempengaruhi tingkat kepatuhan yaitu status pekerjaan ibu, jenis kelamin anak-anak, dan umur anak-anak. Simpulan: Tingkat kepatuhan konsumsi suplemen mikronutrien dalam bentuk bubuk dan permen jelly hampir sama. Oleh karena itu, permen jelly yang difortifikasi dapat digunakan sebagai alternatif suplemen mikronutrien untuk mengatasi masalah gizi di Indonesia.
\end{abstract}

KATA KUNCI: tingkat kepatuhan; permen jelly; mikronutrien; taburia

Korespondensi: Lily Arsanti Lestari, Departemen Gizi Kesehatan, Fakultas Kedokteran, Kesehatan Masyarakat, dan Keperawatan Universitas Gadjah Mada, J1. Farmako, Sekip Utara Yogyakarta 55281 Indonesia; Tel./Fax.: +62-274-547775; e-mail: lily_al@ugm.ac.id

Cara sitasi: Fauzia FR, Farmawati A, Lestari LA. Kepatuhan konsumsi suplemen mikronutrien tidak terpengaruh oleh bentuk suplemen. Jurnal Gizi Klinik Indonesia. 2019;16(2):81-86. doi: 10.22146/ijcn.27617 


\section{PENDAHULUAN}

Menurut data Riset Kesehatan Dasar (Riskesdas) tahun 2013, rata-rata prevalensi anak malnutrisi masih tinggi yaitu $37,2 \%$ anak balita pendek (stunting), $12,1 \%$ anak balita kurus (wasting), 11,9\% anak balita overweight, 21,7\% anemia gizi besi pada wanita usia subur, dan $28,1 \%$ anemia pada balita $(1,2)$. Defisiensi beberapa mikronutrien dapat memberikan dampat buruk pada anak-anak, terutama pada anak dengan status gizi pendek, kurus, atau overweight. Salah satu upaya mengatasi masalah gizi yaitu melalui kegiatan Gerakan 1000 Hari Pertama Kehidupan (HPK) yang di dalamnya terdapat intervensi gizi sensitif yaitu suplementasi Taburia dan fortifikasi pangan $(3,4)$.

Penyebab program suplementasi mikronutrien dalam bentuk tabur (sprinkle) masih belum berjalan yaitu adanya masalah distribusi, daya terima anak yang masih rendah karena terjadi perubahan warna, aroma, dan rasa pada makanan yang diberi sprinkle serta kesulitan ibu atau pengasuh dalam persiapan penyajian (5). Program suplementasi Taburia di Kota Makasar juga masih belum efektif karena persentase ketidakpatuhan dalam pemberian Taburia yang tinggi yaitu sebesar 78,95\% (6). Di Sukoharjo, ibu sering lupa tidak memberikan Taburia setiap 2 hari sekali, perubahan rasa dan bau pada makanan sehingga 59,65\% kepatuhan tidak cukup baik (inadequate) dan 42,11\% tercatat tidak menghabiskan makanan yang sudah ditambahkan Taburia $(7,8)$.

Permen NutriCandy yang pernah diterapkan di India dapat menurunkan prevalensi anemia kekurangan gizi besi pada anak prasekolah, usia sekolah, dan wanita usia subur sebesar 50\% dengan tingkat kepatuhan yang sangat tinggi (90\%) (9). Program pemerintah India tersebut dapat juga diterapkan di Indonesia karena permintaan suplemen dalam bentuk permen jelly sudah cukup tinggi yaitu $70 \%$ dan memiliki daya terima yang baik pada anak balita. Suplemen mikronutrien yang berisi multivitamin dan mineral dalam bentuk permen jelly ini belum pernah ada di Indonesia. Fortifikasi permen jelly dengan 1-2 vitamin dan mineral (misalnya vitamin $\mathrm{C}$ dan kalsium saja) sudah pernah dilakukan, tetapi permen jelly yang dikembangkan pada studi ini memiliki kebaruan dalam hal kandungan 12 jenis vitamin dan 4 jenis mineral. Selain itu, permen jelly ini juga ditambahkan prebiotik fruktooligosakarida yang dapat meningkatkan penyerapan mineral. Tujuan penelitian ini adalah untuk melakukan inovasi bentuk suplemen mikronutrien yang sebelumnya berbentuk bubuk diubah menjadi permen jelly serta untuk mengetahui tingkat kepatuhan konsumsi suplemen mikronutrien tersebut.

\section{BAHAN DAN METODE}

\section{Desain dan subjek}

Desain penelitian yang digunakan yaitu quasi eksperimen dengan randomized control group design. Permen jelly dibuat di Laboratorium Penelitian dan Pengujian Terpadu (LPPT) Universitas Gadjah Mada sedangkan lokasi pemberian intervensi berupa Taburia dan permen jelly yang difortifikasi Taburia yaitu di Taman Kanak-kanak (TK) Islam Plus Mutiara dan Kelompok Bermain (KB) Al-Muthiin Yogyakarta. Besar sampel penelitian adalah 18 anak per kelompok. Metode penentuan sekolah dengan teknik purposive sampling dan penentuan perlakuan Taburia atau permen jelly dengan cara acak. Kriteria inklusi subjek adalah balita usia 36-59 bulan, dinyatakan sehat oleh dokter umum, sudah pernah mengkonsumsi Taburia atau suplemen lain, bersedia menjadi subjek penelitian, dan mendapatkan persetujuan dari orang tua atau wali dengan mengisi dan menandatangani informed consent. Kriteria eksklusi yaitu anak sakit, gizi buruk, dan menderita penyakit infeksi. Diagram alir pengambilan sampel penelitian dapat dilihat pada Gambar 1.

\section{Pengumpulan dan pengukuran data}

Bahan yang digunakan yaitu Taburia dan permen jelly. Taburia mengandung 12 vitamin dan 4 mineral dan berupa bubuk atau sprinkle yang diperoleh dari Kementerian Kesehatan RI. Taburia dan permen jelly dibagikan setiap minggu dengan aturan konsumsi 2 hari sekali. Kandungan mikronutrien dalam permen jelly berasal dari Taburia yang dimasukkan dalam permen dan ditambahkan fruktooligosakarida (FOS) sebanyak 1 g. Kandungan mikronutrien pada 3 butir permen jelly diperkirakan setara dengan $1 \mathrm{~g}$ Taburia. Alat yang digunakan dalam penelitian yaitu seperangkat alat untuk membuat permen jelly, timbangan berat badan digital 


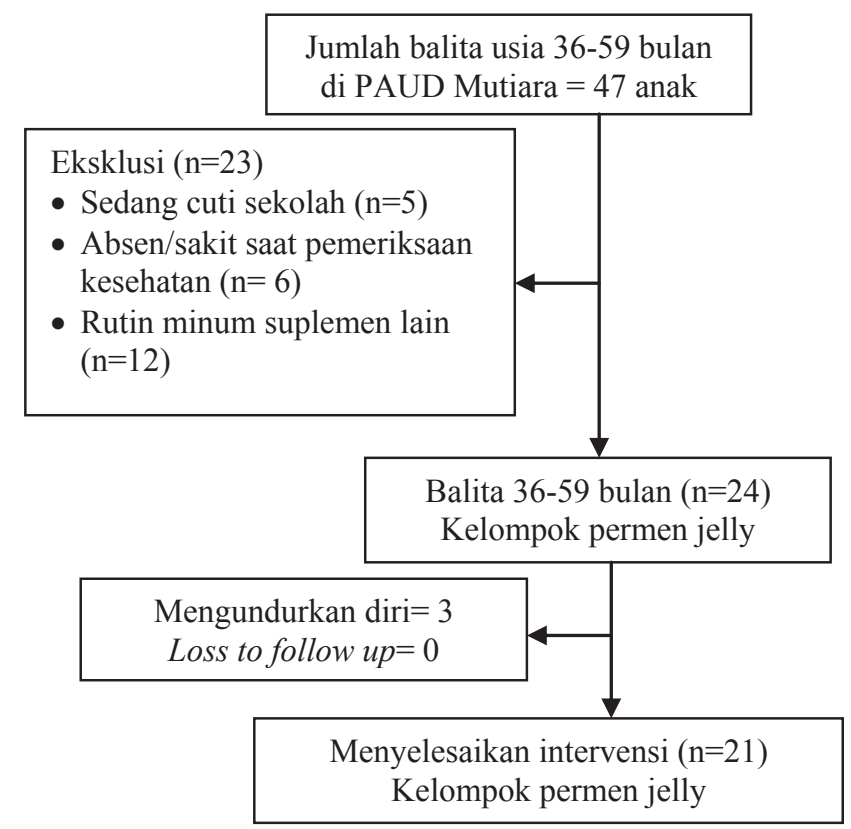

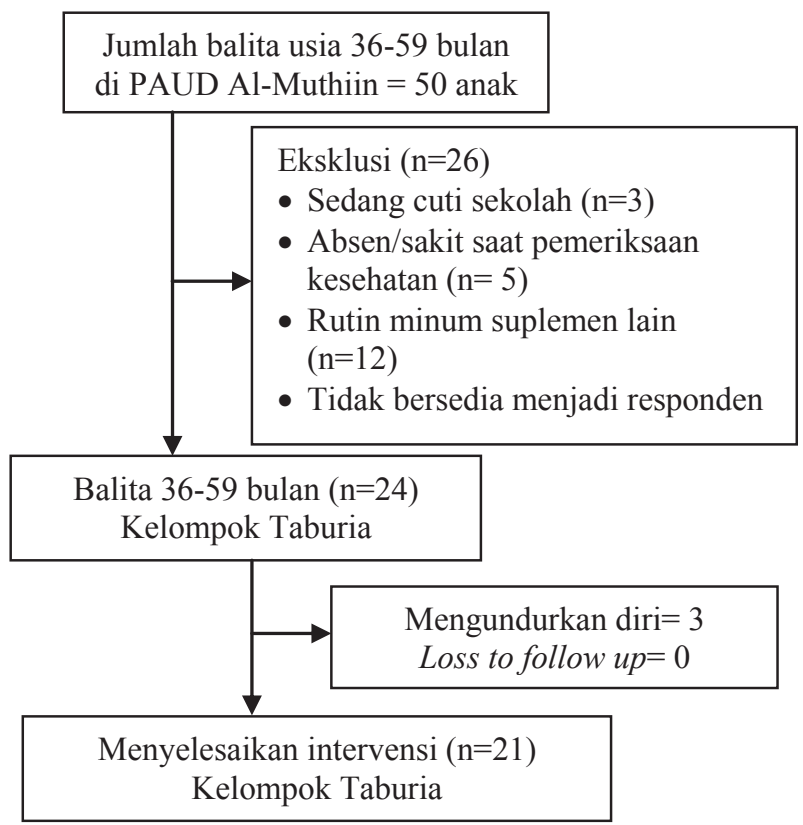

Gambar 1. Diagram alir pengambilan sampel penelitian yang sudah dikalibrasi di LPPT Universitas Gadjah Mada, dan kaliper.

Penilaian tingkat kepatuhan konsumsi mikronutrien dengan melihat rata-rata dari jumlah bungkus atau sachet mikronutrien yang dikonsumsi per anak sesuai dengan aturan konsumsi, dosis pemberian, besar porsi mikronutrien yang dihabiskan pada kelompok kontrol (Taburia) dan kelompok intervensi (permen jelly). Skala pengukuran kepatuhan konsumsi adalah sangat patuh $\geq 80 \%$, patuh 50-79\%, dan kurang patuh 20-49\%. Ibu atau pengasuh yang anaknya menjadi responden penelitian ini diberi buku panduan dan catatan harian yang berisi biodata anak, status demografi keluarga balita, formulir pencatatan kepatuhan konsumsi Taburia atau permen jelly, dan formulir laporan evaluasi pemberian mikronutrien. Buku tersebut disimpan ibu atau pengasuh anak selama 30 hari intervensi. Penelitian ini telah mendapatkan ijin dari Komisi Etik Penelitian Biomedis Manusia Fakultas Kedokteran Universitas Gadjah Mada dengan nomor KE/FK/0143/EC/2017.

\section{Analisis data}

Data dari buku panduan dan catatan harian diolah dan dianalisis secara statistik menggunakan aplikasi STATA 13. Analisis statistik yang digunakan adalah
Tabel 1. Karakteristik balita pada kelompok Taburia dan permen jelly $(n=42)$

\begin{tabular}{|c|c|c|c|}
\hline \multirow[b]{2}{*}{ Variabel } & \multicolumn{2}{|c|}{ Bentuk suplemen (Rerata \pm SD) } & \multirow[b]{2}{*}{$\mathbf{p}^{1}$} \\
\hline & $\begin{array}{c}\text { Taburia } \\
(\mathrm{n}=21)\end{array}$ & $\begin{array}{l}\text { Permen jelly } \\
(n=21)\end{array}$ & \\
\hline Usia (bulan) & $45,81 \pm 6,9$ & $50,67 \pm 6,3$ & 0,030 \\
\hline $\mathrm{BB}(\mathrm{kg})$ & $14,93 \pm 2,2$ & $15,65 \pm 1,3$ & 0,195 \\
\hline $\mathrm{TB}(\mathrm{cm})$ & $100,67 \pm 5,5$ & $102,14 \pm 3,9$ & 0,318 \\
\hline $\mathrm{IMT} / \mathrm{U}^{2}$ & $-0,56 \pm 0,7$ & $-0,23 \pm 1,05$ & 0,229 \\
\hline \multicolumn{4}{|l|}{ Jenis kelamin } \\
\hline Laki-laki & 13 & 6 & 0,030 \\
\hline Perempuan & 8 & 15 & \\
\hline
\end{tabular}

${ }^{1}$ Independent $t$-test;

${ }^{2}$ Klasifikasi status gizi normal ( $z$-score $\geq-2 \mathrm{SD} s / \mathrm{d} \leq 2 \mathrm{SD}$ )

$\mathrm{BB}=$ berat badan; $\mathrm{TB}=$ tinggi badan;

$\mathrm{IMT} / \mathrm{U}=$ indeks massa tubuh berdasarkan umur

Independent t-test, Chi-Square test, dan Fisher's exact test dengan nilai signifikansi sebesar $\mathrm{p}<0,05$ pada $\mathrm{CI}=95 \%$.

\section{HASIL}

Status gizi balita pada penelitian ini tergolong normal dan tidak berbeda antarkelompok Taburia dan permen jelly. Rerata usia dan jenis kelamin anak balita pada kedua kelompok berbeda signifikan. Usia anak balita pada kelompok permen jelly 5 bulan lebih tua dibanding 
Tabel 2. Distribusi frekuensi karakteristik ibu responden

\begin{tabular}{|c|c|c|c|c|c|}
\hline \multirow{2}{*}{ Variabel } & \multicolumn{2}{|c|}{ Taburia $(n=21)$} & \multicolumn{2}{|c|}{ Permen jelly $(n=21)$} & \multirow[b]{2}{*}{$\mathbf{p}$} \\
\hline & $\mathbf{n}$ & $\%$ & $\mathbf{n}$ & $\%$ & \\
\hline \multicolumn{6}{|l|}{ Pendidikan } \\
\hline Rendah ( $\leq$ SMP $)$ & 8 & 38,10 & 9 & 42,86 & $0,753^{\mathrm{a}}$ \\
\hline Tinggi ( $\geq \mathrm{SMA}$ ) & 13 & 61,90 & 12 & 57,14 & \\
\hline \multicolumn{6}{|l|}{ Pekerjaan } \\
\hline Ibu rumah tangga & 17 & 80,95 & 8 & 38,10 & $0,0001^{\mathrm{b}}$ \\
\hline Swasta/wiraswasta & 4 & 19,05 & 11 & 52,38 & \\
\hline PNS & 0 & 0 & 2 & 9,52 & \\
\hline \multicolumn{6}{|c|}{ Pengeluaran rumah tangga } \\
\hline Rendah $(<1$ juta $)$ & 7 & 33,33 & 2 & 9,52 & $0,119^{b}$ \\
\hline Sedang (1-2 juta) & 9 & 42,86 & 9 & 42,86 & \\
\hline Tinggi (lebih 2 juta) & 5 & 23,81 & 10 & 47,62 & \\
\hline
\end{tabular}

usia anak pada kelompok Taburia. Proporsi anak laki-laki pada kelompok Taburia lebih banyak dibanding kelompok permen jelly (Tabel 1).

Sebagian besar ibu dari responden pada kelompok Taburia bekerja sebagai ibu rumah tangga (80,95\%) sedangkan pada kelompok permen jelly sebagian besar ibu bekerja sebagai karyawan swasta atau wiraswasta $(52,38 \%)$ dengan nilai $\mathrm{p}<0,05$ (Tabel 2 ).

Tingkat kepatuhan konsumsi suplemen mikronutrien jika dilihat dari rerata jumlah bungkus atau sachet mikronutrien yang dikonsumsi per anak sesuai dengan aturan konsumsi dan dosis pemberian, maka diperoleh hasil kepatuhan konsumsi suplemen mikronutrien dalam bentuk Taburia adalah sebesar $85,39 \pm 16,55 \%$ dan dengan bentuk permen jelly sebesar $80,32 \pm 15,70 \%$. Tidak terdapat perbedaan yang signifikan pada tingkat kepatuhan konsumsi suplemen mikronutrien dalam bentuk tabur maupun permen jelly ( $\mathrm{p}=0,3136)$. Lebih lanjut, Gambar 2 menunjukkan bahwa persentase responden yang menghabiskan suplemen lebih banyak pada kelompok permen jelly $(52,38 \%)$ dibanding kelompok Taburia (23,81\%). Namun demikian, jika data suplemen yang habis semua digabung dengan yang habis $3 / 4$ maka antara kelompok permen jelly dan Taburia hanya terpaut $9,78 \%$ yaitu kelompok permen jelly sebesar 80,95\% dan kelompok Taburia 71,17\%. Oleh karena itu, hasil pengujian tingkat kepatuhan konsumsi Taburia dan permen jelly tidak berbeda signifikan.

Keterangan: Permen jelly yang diberikan sebanyak 3 butir per 2 hari sedangkan Taburia 1 sachet per 2 hari,

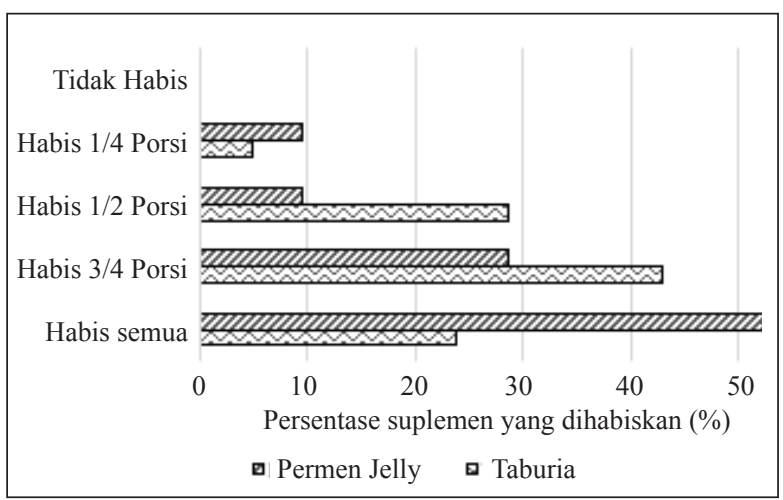

Gambar 2. Persentase jumlah suplemen yang dihabiskan

dengan kandungan mikronutrien yang setara antara permen jelly dan Taburia. Pengujian statistik dengan Fisher's exact test memberikan nilai $\mathrm{p}=0,009$.

\section{BAHASAN}

Hasil penelitian menunjukkan bahwa tidak ada perbedaan yang signifikan pada persentase kepatuhan konsumsi mikronutrien antara bentuk bubuk (Taburia) dengan bentuk permen jelly, meskipun rerata kepatuhan sedikit lebih tinggi pada kelompok Taburia. Hal ini diduga karena faktor pekerjaan ibu yaitu jumlah ibu rumah tangga di kelompok Taburia yang lebih banyak (80,95\%) daripada kelompok permen jelly $(38,10 \%)(p<0,05)$. Ibu rumah tangga memiliki waktu yang lebih banyak bersama dengan anak sehingga dapat melihat langsung proses tumbuh kembang dan permasalahan yang dialami anak. 
Hasil penelitian ini sejalan dengan penelitian sebelumnya (10) yang menyatakan bahwa ibu rumah tangga memiliki kepatuhan konsumsi biskuit sebesar 2,31 kali lebih tinggi daripada ibu yang bekerja ( $\mathrm{p}>0,05)$.

Hasil penelitian ini juga membuktikan bahwa jenis kelamin mempengaruhi kepatuhan konsumsi mikronutrien $(p<0,05)$. Anak laki-laki dan perempuan mempunyai sifat dasar yang berbeda yaitu anak laki-laki cenderung lebih yakin dan tidak mudah dipengaruhi oleh teman sebayanya $(11,12)$. Penelitian lain juga menjelaskan bahwa anak balita laki-laki 1,38 kali lebih patuh dibandingkan balita perempuan terhadap pemberian mikronutrien dalam bentuk biskuit dan suplemen (10). Jumlah anak laki-laki lebih banyak di kelompok Taburia sedangkan anak perempuan lebih banyak di kelompok permen jelly. Selain sifat dasar anak laki-laki yang lebih mudah mengonsumsi multivitamin mineral, jenis makanan yang disukai antara anak laki-laki dan perempuan juga berbeda. Anak laki-laki lebih menyukai makanan olahan yang berbahan dasar daging dan telur $(p<0,001)$ sedangkan pada anak perempuan lebih menyukai makanan dengan melihat bentuk dan warna yang menarik atau lucu, atau juga lebih suka rasa manis pada permen $(\mathrm{p}<0,005)(9)$.

Daya terima anak terhadap permen jelly yang difortifikasi juga mempengaruhi tingkat kepatuhan konsumsi. Studi sejenis (13) yang meneliti daya terima permen jelly yang difortifikasi Taburia dengan menggunakan ekpresi wajah anak setelah mengkonsumsi permen yang dinilai oleh orang tua/pengasuh maupun peneliti menunjukkan bahwa rerata daya terima permen jelly adalah 2,77. Artinya, anak-anak agak suka terhadap permen jelly yang diberikan. Beberapa anak balita menyatakan tidak suka terhadap permen jelly karena terdapat rasa dan aroma yang tidak enak seperti obat.

Faktor usia balita juga bisa menjadi salah satu penyebab besar porsi permen jelly yang dihabiskan lebih besar daripada konsumsi Taburia $(\mathrm{p}<0,05)$. Anak usia 4 sampai 24 bulan pada semua jenis kelamin dalam menghadapi jenis makanan baru, akan muncul rasa penasaran (neofilia) dan rasa curiga terhadap suatu makanan baru (neophobia) (12). Anak usia 2 sampai 4 tahun cenderung menyukai makanan dengan tekstur renyah sedangkan anak dengan usia 4 sampai 5 tahun cenderung menyukai makanan lunak atau berair (14). Pada kelompok permen jelly didominasi balita usia 49-59 bulan yang pada usia tersebut anak lebih menyukai tekstur makanan lunak dan kelompok Taburia didominasi balita 36-48 bulan yang lebih menyukai tekstur makanan renyah.

\section{SIMPULAN DAN SARAN}

Kesimpulan dari penelitian ini adalah bentuk suplemen tidak berpengaruh signifikan terhadap tingkat kepatuhan konsumsi mikronutrien balita. Saran untuk penelitian selanjutnya yaitu perlu adanya perbaikan formulasi permen jelly agar tidak tercium bau vitamin dan mineral yang menyengat, misalnya dengan menggunakan pre-mix mikronutrien yang lain.

\section{UCAPAN TERIMA KASIH}

Terima kasih kepada Kementerian Riset, Teknologi, dan Pendidikan Tinggi yang telah memberikan dana penelitian melalui skema Penelitian Unggulan Perguruan Tinggi (PUPT) dengan nomor kontrak 2379/UN1.P.III/ DIT-LIT/LT/2017 yang diberikan kepada Dr. Lily Arsanti Lestari, STP., MP dengan judul penelitian "Pengembangan produk pangan dan farmasetik nasional berbasis gelatin halal dari bahan baku lokal" melalui Grup Riset Halal LPPT UGM.

\section{Pernyataan konflik kepentingan}

Para penulis menyatakan tidak ada konflik kepentingan dan telah menyetujui untuk publikasi pada Jurnal Gizi Klinik Indonesia.

\section{RUJUKAN}

1. Badan Litbangkes, Kemenkes RI. Riskesdas dalam angka Daerah Istimewa Yogyakarta tahun 2013. [series online] 2013 [cited 2017 Juni 12]. Available from: URL: http:// www.pusat2.litbang.depkes.go.id/pusat2_v1/wp-content/ uploads/2015/02/Riskesdas-Dalam-Angka-Prov-DIY.pdf

2. Kemenkes RI. Kesehatan dalam kerangka Sustainable Development Goals (SDGs). Jakarta: Departemen Kesehatan RI; 2015.

3. Sohaimy S. Functional foods and nutraceuticals-modern approach to food science. World Appl Sci J. 2012;20(5):691708. doi: 10.5829/idosi.wasj.2012.20.05.66119 
4. World Health Organization, Regional Office for South-East Asia. Regional nutrition strategy: addressing malnutrition and micronutrient deficiencies (2011-2015). [series online] 2012 [cited 2017 Juni 12]. Available from: URL: https:// apps.who.int/iris/handle/10665/205804

5. Umniyati H. Sprinkles: strategi baru pengendalian defisiensi zat besi dan anemia pada bayi dan anak di negara berkembang. Kesmas: Jurnal Kesehatan Masyarakat Nasional. 2011;5(5):195-200. doi: 10.21109/kesmas. v5i5.126

6. Alim A, Thaha R, Citrakesumasari. Evaluating ground provision taburia in the City of Makassar in 2011. [series online] 2011 [cited 2017 Juni 12]. Available from: URL: http://pasca.unhas.ac.id/jurnal/files/ fbe47c599de0f2c7f983f6c360cc6c3b.pdf

7. Chasanah LI. Hubungan tingkat kepatuhan pemberian taburia terhadap peningkatan berat badan anak usia 6-24 bulan di Desa Demakan Kecamatan Mojolaban Kabupaten Sukoharjo [Skripsi]. Surakarta: Universitas Muhammadiyah Surakarta; 2014.

8. Rauf S, Faramitha. Pengaruh pemberian taburia terhadap perubahan status gizi anak gizi kurang umur 12-24 bulan di Kecamatan Pangkajene Kabupaten Pangkep tahun 2010. Media Gizi Pangan 2012:13(1):1-6.
9. De-Regil LM, Suchdev PS, Vist GE, Walleser S, PeñaRosas JP. Home fortification of foods with multiple micronutrient powders for health and nutrition in children under two years of age. Cochrane Database Syst Rev. 2011;(9):CD008959. doi: 10.1002/14651858. CD008959.pub2

10. Muslihah N, Khomsan A, Briawan D, Riyadi H. Kepatuhan konsumsi suplemen gizi berbasis lipid dosis kecil pada bayi di Perdesaan, Kabupaten Bangkalan. Jurnal Gizi Pangan. 2016;11(2):115-24.

11. Patterson JM, Wall M, Berge J, Milla C. Gender differences in treatment adherence among young with cystic fibrosis: development of a new questionnaire. J Cyst Fibros. 2008 Mar;7(2):154-64. doi: 10.1016/j.jcf.2007.07.008

12. Cooke LJ, Wardle J. Age and gender differences in children's food preferences. Br J of Nutr. 2005;93(5):741-6. doi: 10.1079/bjn20051389

13. Fluorensia BF, Lestari LA, Ermamilia A. Pengaruh perbandingan konsentrasi gelatin dan glukomanan konjak serta fortifikan taburia-fruktooligosakarida terhadap sifat sensori permen jelly dan daya terima anak [Skripsi]. Yogyakarta: Universitas Gadjah Mada; 2017.

14. Nicklaus S, Issanchou S. Understanding consumer of food products. Cambridge, U.K.: Woodhead Publishing; 2007. 